\title{
DEVELOPMENT OF A NOVEL MIXED FLOW DRYER DESIGN
}

\author{
Author(s): \\ F. Weigler - H. Scaar - G. Franke - J. Mellmann
}

\author{
Affiliation: \\ Department of Postharvest Technology, Leibniz Institute for Agricultural Engineering Potsdam-Bornim, Max-Eyth-Allee \\ 100, Potsdam 14469, Germany
}

Email address:

fweigler@atb-potsdam.de, hscaar@atb-potsdam.de,gfranke@atb-potsdam.de,jmellmann@atb-potsdam.de

\begin{abstract}
Mixed flow dryers (MFD) are widely used in agriculture for the drying of various crops including maize and rice. As compared to other drying methods in the industrial drying, mixed flow dryers still have considerable potential for improving energy efficiency. The comparatively high primary energy consumption is mainly caused by uneven drying, which, in turn, is caused less by poor dryer control rather than by unfavorable dryer design. In order to optimize the processes in agricultural engineering, such as the mixed flow dryer, numerical methods are being increasingly used. Optimizing of the dryer geometry provides a high potential to further increase the efficiency of MFD.
\end{abstract}

\section{Keywords}

Mixed Flow Dryer, grain drying, numerical methods, experimental validation

\section{Introduction}

The majority of research papers published on mixed-flow drying were focused on how to increase the dryer performance and to save product quality, e. g. by improving the dryer control. Bruce [1] applied a multiple-bed computer simulation to model the dryer as a series of concurrent and counter-current elements. This model was successfully employed to predict the general behavior of the dryer and the influence of operating variables on dryer performance.

Early studies on the influence of different air duct geometries on the particle flow have been carried out by Maltry [2] and Klinger [3] using colored grains. However, their conclusions are just based on qualitative analyses. Chaabouni et al. [4] examined the bulk movement in MFD based on a residence time analysis with colored tracer particles. As they could demonstrate experimentally for the first time, the particles in the center of the dryer flow faster as particles close to the wall. To study segment processes and to mathematically model the MFD, relatively few work was done so far. Cenkowski, Miketinac, and Kelm [5] simulated and measured airflow patterns and isobars in a fullscale section of a conventional mixed-flow dryer. The differential equation system derived was solved using the finite element method. Even though a semi-empirical relationship for a static bed was implemented, the authors achieved an acceptable agreement with the measurements.
More recently, the number of papers related to basic research on MFD increased. Cao et al. [6] used a simulation model in order to investigate the effect of structural and operating parameters on the performance and energy consumption of a mixed-flow grain dryer. The conducted simulations were based on a twodimensional dryer model which has been developed in a previous work. The authors put special emphasis into the study of the effect of structural parameters such as size and shape of air ducts, spacing between air ducts, number of rows of air ducts, and column height. As they revealed, small air ducts are better than large air ducts, amongst others.

Kocsis et al. [7] reported on experimental findings of the influence of air ducts and side walls on grain flow. Particle velocity and mass flow distributions were measured at a MFD test station equipped with a transparent acrylic glass front wall. As could be demonstrated the particle flow through the center of the dryer is faster than at the side walls. In order to investigate the bulk motion and thus the distributions of the particle velocity and the residence time in a MFD precisely, Iroba et al. [8] and Weigler et al. [9] developed two-dimensional models based on the Discrete Element Method (DEM). Using the discrete calculations particle trajectories in a mixed flow dryer were determined. The model predictions confirmed the experimental results obtained from particle flow measurements and certified that particles in the center of the dryer flow faster than those in the near wall regions. This phenomenon is known as core flow effect causing inhomogeneous particle flow. As a consequence, non-uniform drying occurs which is characterized by strong fluctuations of the grain moisture distribution over the cross section at the dryer outlet [10]. Particles having a higher velocity and lower residence time are under-dried, while particles with a lower velocity and, thus, a high residence time are over-dried. Therefore, it is necessary to optimize the geometry of the mixed flow dryer apparatus and to improve the drying process. In this way, drying costs and quality losses due to over-drying can be reduced and the formation of mold and toxins in storage due to under-drying can be avoided.

The present paper is aimed to evaluate the new developed design with respect to medium flow. For it, the experimental and numerical results obtained for the traditional and new design are compared with each other. The advantages and disadvantages of the new geometry are discussed.

The optimized dryer design should include the following enhancements: 
-multi-stage product cross mixing,

-increasing the heat and mass transfer and thus,

-increasing the drying capacity,

-reduction of energy consumption,

- homogeneous drying conditions and thus,

- uniform product quality.

Through product-specific optimization of the novel dryer geometry and multi-stage product cross mixing drying performance compared to the traditional design can be significantly increased. The aim is to develop a high-performance dryer.

\section{Numerical methods}

The MFD which is analyzed consists of a vertical drying shaft, in which the inlet and outlet air ducts are horizontally arranged (Figure 1 and 2). The drying air flow is controlled by the staggered inlet and outlet air ducts. The material is charged from the top of the dryer and flows vertically downwards by gravity. The discharge device on the bottom of the dryer regulates the product mass flow rate.

\section{Discrete Element Method (DEM)}

The DEM describes the mechanical behaviour of bulk materials based on discrete structures (single particle). As compared to the finite element or finite volume method, the DEM works without any grid matrix. In the calculation the flow behavior of the bulk material is specified with Newton's law to the particles and a force-displacement law at the contacts between them. The mechanical behavior of an assembly of particles is described by tracing the movement of individual particles. The DEM was introduced by Cundall [11] and then applied to soils by Cundall and Strack [12]. It computes the particle flow numerically by an explicit time integration scheme with suitable boundary and initial conditions. In this work, a commercial software called PFC 2DC was used to simulate the solid mass flow in MFDs on a discrete way. To describe the real behavior of wheat particles, clumps were formed from spheres which are connected with each other. Every clump has an ellipsoidal shape and a length of $5.6 \mathrm{~mm}$ and a high of $3 \mathrm{~mm}$. The mechanical properties of the clumps correspond to those of grains according to Mühlbauer [13].

\section{Computational Fluid Dynamics (CFD)}

The commonly used method for CFD calculations is the Finite Volume Method (FVM). This method calculates the fluid flux properties of the investigated system by the conservation laws for mass, momentum and energy. To discretize the differential equations, a grid matrix of the computational domain (called mesh) was created. Thereafter, boundary and initial conditions were defined for the borders of the domain, and the conservation equations were approximated to the mesh by the Gaussian Integral Theorem. When calculating the air flow in MFD, the bed was considered as a porous medium. The porosity of the bulk grain has been determined according to Matthies [14]. The specific pressure drop was determined using the Ergun equation based on measured values. For the inlet air ducts, an experimental determined flow velocity was used as initial condition for the air flow.

\section{Experimental investigation}

The experimental investigation of traditional and the newly developed geometries were performed on pilot-scale dryers at the Leibniz Institute for Agricultural Engineering. For this purpose, two traditional geometries were examined having the following geometric differences (see Figure $1 \mathrm{a}, \mathrm{b}$ ):

\section{-roof size \\ -roof number \\ - distance between the roofs.}

The two dryers with traditional geometry consist of a vertical shaft with a height of about $2 \mathrm{~m}$, a width of $0.6 \mathrm{~m}$ and a depth of $0.4 \mathrm{~m}$. Roof-shaped ducts for inlet and exit air were uniformly arranged in the dryer shaft. Horizontal rows with half air ducts on the side walls alternate with those without half air ducts.

The traditional geometry 1 (see Figure 1a) is characterized by large roofs with a large distance between the roofs resulting in a low number of air ducts. As compared to industrial scale, this dryer has a reduced shaft dimension while maintaining the original roof size. Hence, it represents a sector of an industrial dryer. The traditional geometry 2 (see Figure $1 \mathrm{~b}$ ) is characterized by small roofs with a low distance between the roofs and a resulting high roof number. This dryer is a scaled (1:5) industrial dryer.

The dryer with the newly developed geometry (Figure 1c) consists of a vertically arranged dryer shaft with inclined walls. The direction of inclination of section changes from section to section. The dryer shaft has a height of about $2 \mathrm{~m}$, width of 0.74 $\mathrm{m}$, a total with a useful width of $0.6 \mathrm{~m}$ and a depth of $0.4 \mathrm{~m}$. The air ducts are triangular in shape and arranged in horizontal rows. One section consists of 3 air duct rows. Each row consists of 6 full and 1 half air duct. The sections are alternately turned by $180^{\circ}$.

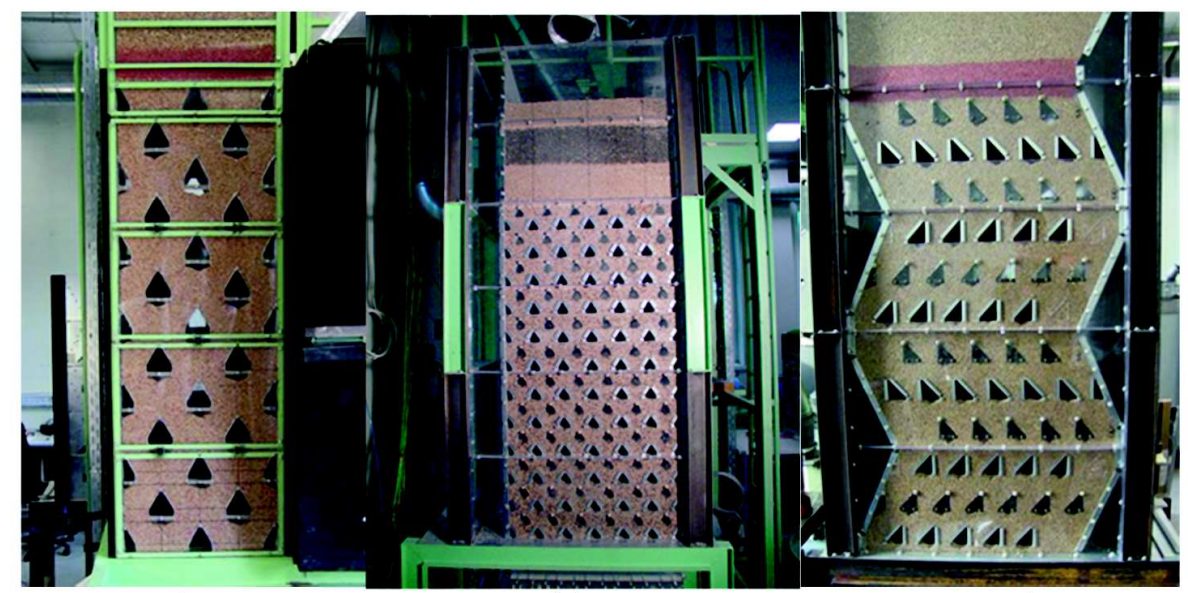

a.) c.)

Figure 1. Experimental pilot scale dryers at ATB Potsdam:

a) traditional geometry 1, b) traditional geometry 2 , c) newly developed geometry 
The test dryers are equipped with a pneumatically operated discharge gate providing an even grain flow over the crosssection. The front wall of the grain flow study equipment is made of transparent acrylic glass (Figure 1) enabling to visually observe the movement of the particles. Coloured wheat was used as tracer particles. To measure the particle velocity profiles a digital video camera was employed. Wheat was used as bed material with an average moisture content of about $14 \% \mathrm{w}$. b. and a bulk density of $780 \mathrm{~kg} \cdot \mathrm{m}^{-3}$.

At the beginning of the experiments, the dryer was completely filled with wheat and then emptied by using the discharge system. To observe the particle motion, a horizontal layer of coloured (red or black) wheat grains with a height of $150 \mathrm{~mm}$ was applied on top of the grain bed. The reproducibility of the experiments was confirmed by repeating the experiments. The tests were carried out to compare the particle flow profiles of the coloured particles.

\section{Results}

Figure 2 shows an experimental (a) and a numerical (b) discharge process observed and simulated at geometry 1, respectively, illustrating the resulting flow profile in the dryer. As can be clearly seen from the pictures, a pronounced particle velocity distribution was formed over the dryer width showing a so-called V-shaped profile. This means, the grains in the centre of the dryer flow faster than those near the side walls. This flow profile is caused by the interaction between the particles and the side walls with half air ducts. The big size of the roofs and the large spacing's between them favour the enormous forming of the profile.

As the simulated particle trajectories illustrate (Figure 2c), streaks of particles exist between the ducts without any crossmixing over the dryer height. Considering the actual airflow distribution, this channelling and the different residence times between the centre and wall regions will result in a non-uniform moisture distribution at the dryer outlet.

Similarly, Figure 3 shows an experimental (a) and a numerical (b) flow profile obtained at geometry 2 of the test dryer. Again, two flow zones are visible in the dryer: a relatively wide core flow region in the center and the near wall regions with a pronounced velocity distribution. However, due to the smaller roofs and the lower spacing's between them, the core zone is more pronounced as compared to geometry 1 consisting of a more homogeneous flow profile. The near-wall flow profiles are due to the interaction of the grain with the dryer wall and the half air ducts. As the simulated particle trajectories illustrate (Figure 3c), streaks of particles exist between the ducts without any cross-mixing over the dryer height.

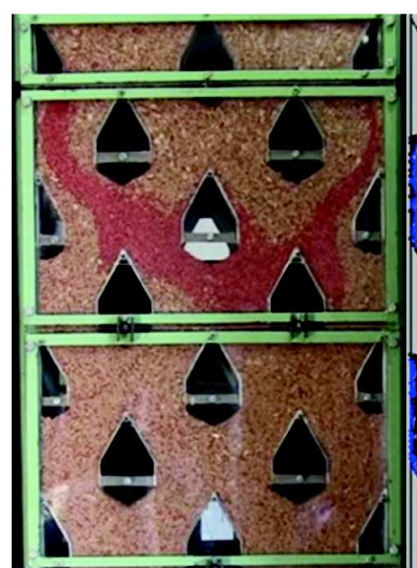

a)

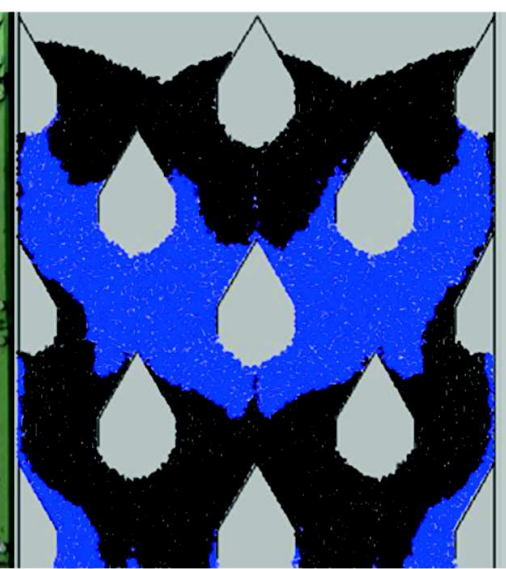

b)

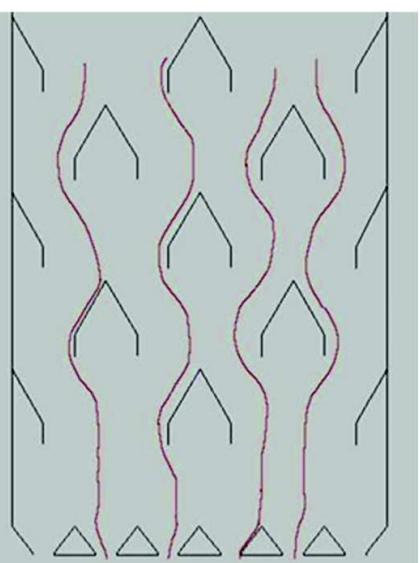

c)

Figure 2. Particle flow investigations for geometry 1: a) Experimental. b) Numerical. c) Particle trajectories.

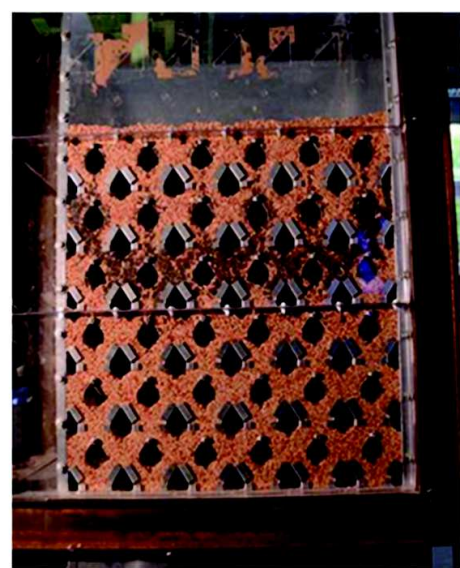

a)

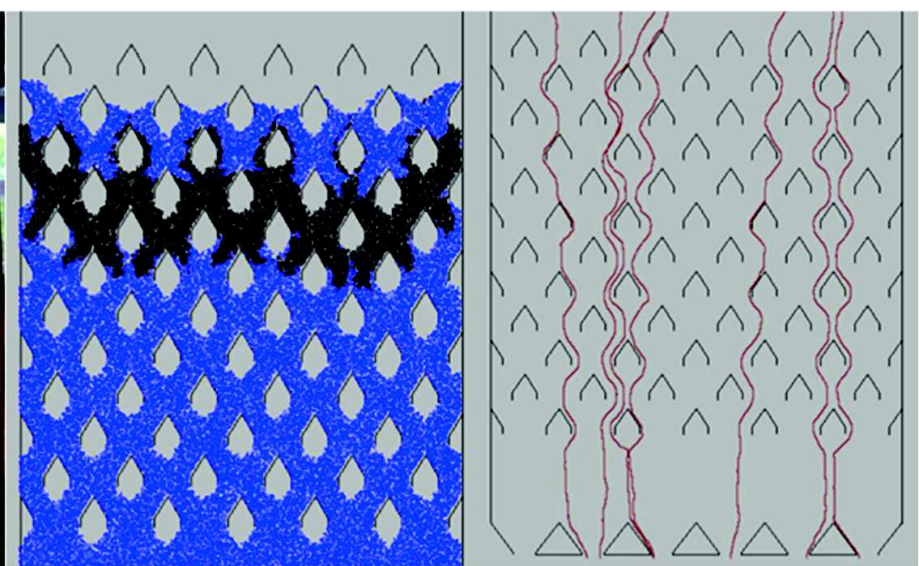

b) c)

Figure 3. Particle flow investigations for geometry 2: a) Experimental. b) Numerical. c) Particle trajectories.

As the particle flow investigations revealed, a flow profile also exists over the depth of the dryer. The tracer particles inside the dryer were observed to flow much faster than those at the transparent acrylic glass front wall. This means, that a flow profile was formed over the entire cross section of the dryer comparable to the core flow in a silo.

The numerical and experimental results obtained from the particle flow investigations revealed that wall friction has a large 
effect on the grain flow in MFD. The results show that two regions exist: a near wall region and a central region. Grains in the center of the dryer have higher velocities and are delivered faster while grains close to the side walls have reduced velocities because of wall friction. As the comparison between simulated and experimental results showed as well, the Discrete Element Method can adequately predict the main features of particle flow. Therefore, it is possible to obtain particle trajectories from numerical studies.

The investigations of the air flow for the horizontal configuration shows, that the inlet air from an inlet-air duct will be distributed to the 4 surrounding outlet-air ducts, in which the air-stream to the lower outlet-air ducts is higher than to the upper one. The different residence times of the particles between center and wall region in the dryer result in a moisture distribution at the discharge device of the dryer. These effects were increased by the different flow velocities in the dryer.

\section{Newly developed geometry}

In the drying group of the Leibniz Institute for Agricultural Engineering Potsdam-Bornim (ATB), a new dryer geometry for the MFD [15] was developed (Figure 4a). The new geometry consists of a vertically arranged drying shaft with inclined walls and variable replaceable air ducts. The side walls of the dryer section are inclined to the vertical by a certain angle $\theta$. This angle corresponds to the angle of inclination of the diagonals axes running through the centers of the roofs. The direction of wall inclination changes after each dryer section. Therefore, the direction of the particle flow paths varies from section to section. The particle trajectories are parallel to the diagonal rows of ducts, resulting in an alternating flow around hot inlet and cold exit air ducts (Figure 4b). This increases drying uniformity. The complementary angle of $\theta$ is greater than the angle of repose of most bulk materials, thereby, avoiding bridge formation at the side walls. In addition, the new apparatus design includes a multistage product cross-mixing. This is attained by a lateral displacement of the air duct rows at the interfaces between the sections. The multi-stage product mixing has multiple advantages: the drying potential of the air is by far better utilized, strains of moist particles are resolved, the drying conditions are homogenized and, hence, the drying efficiency is increased.

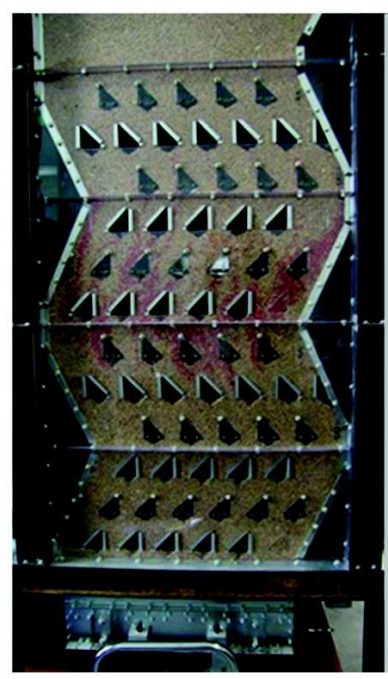

a)

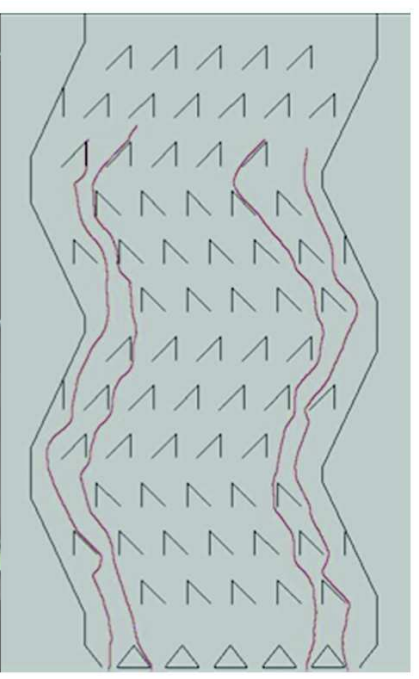

b)
Figure 4. Particle flow investigations at the new geometry: a) Experimental. b) Particle trajectories.
With this arrangement, a systematic generation of regions with low particle velocity near the dryer walls is possible since the inclination increases the wall friction effect. If air ducts are removed in addition, regions with low air velocity occur near the wall. By adjusting particle and air velocities in the near-wall regions and in the center of the dryer, drying uniformity and particle moisture distribution are homogenized over the dryer cross section.

\section{Conclusion}

Experimental and numerical studies on particle flow were conducted to investigate the influence of design elements and to develop the new dryer design. As the results show, the particle flow distribution strongly depends on the dryer shaft and the discharge device. The experiments and simulation of the particle flow of two traditionally designed MFD with grain-shaped particles shows the expected behavior, that the particle flow through the center of the dryer has a higher velocity and lower friction effect. The long tail at the walls revealed the influence of wall friction and the half air ducts positioned directly at the side walls on the grain flow. As a consequence, grains have different residence times resulting in a non-uniform moisture distribution at the outlet of the dryer. Therefore, the shape and arrangement of the air ducts as well as the discharge device require further development to achieve a homogeneous particle flow distribution.

Against this background, our institute designed a new geometry for a MFD. The new design is characterized by sectional inclined side walls and triangular shaped air ducts. The zigzag pattern of the dryer and removable air ducts allow for creating regions with different particle and air velocities. In comparison with the traditional MFD geometry, thereby, we are able to generate regions with low air flow and low particle velocity near the dryer walls and regions with high air flow and high particle velocity in the center of the dryer. As a result, the drying conditions can be adjusted in different parts of the dryer. Hence, the drying process is homogenized. With the newly developed geometry, it is possible to locally adjust both particle and air velocities so as to counteract over-drying near the walls. The multi-stage product cross-mixing increases the drying efficiency. With a homogenized drying, energy can be saved and also the product quality can be improved. The new dryer geometry is further investigated in a succession project.

\section{Acknowledgements}

The authors gratefully thank the German Federal Ministry of Education and Research (BMBF) for funding this work (Project No. FKZ02PK2158).

\section{References}

[1.] Bruce D. M.: 1984. Simulation of Multiple-Bed Concurrent-, Counter-, and Mixed-Flow Grain Driers. Journal of Agricultural Engineering Research, 30, pp. 361-372. http://dx.doi.org/10.1016/S0021-8634(84)80037-2

[2.] Maltry W.: 1966. Einige Untersuchungen zur Aufklärung des Verhaltens von Getreide im Dächer-Schachttrockner. Archiv für Landtechnik 5(3), pp. 223-264

[3.] Klinger J.: 1977. Einige thermodynamische und strömungstechnische Untersuchungen zur Modellierung der Vorgänge in Dächerschachttrocknern für Getreidekörner; Ph.D. Dissertation, TU Dresden

[4.] Chaabouni M., Flick D., Techasena O.: 1992. Particles flow in industrial grain driers. Drying '92. In A. S. Mujumdar (Ed.), Proceedings of the 8th International drying Symposium (IDS'92), 
Montreal, Canada, August 2-5, 1992 (pp. 1409 - 1418). Amsterdam: Elsevier Science Publishers B.V.

[5.] Cenkowski S., Miketinac M., Kelm A.: 1990. Airflow Patterns in a Mixed-Flow Dryer. Journal of Canadian Agricultural Engineering, 32, pp. 85-90.

[6.] Cao C. W., Yang D. Y., Liu Q.: 2007. Research on Modeling and Simulation of Mixed-Flow Grain Dryer. Drying Technology, 25, pp. 681-687. http://dx.doi.org/10.1080/07373930701290951 [7.] Kocsis L., Teodorov T., Mellmann J., Gottschalk K., Mészáros C., Farkas I.: 2008. Analysis of Grain Flow Experiments in a Mixed-Flow Grain Dryer. In Proceedings of the 17th World Congress of International Federation of Automatic Control (IFAC). Seoul, Korea, July 6-11, 2008, pp. 1608-1612.

[8.] Iroba K. L., Mellmann J., Weigler F., Metzger T., Tsotsas E.: 2011. Particle velocity profiles and residence time distribution in mixed-flow grain dryers. Granular Matter 13, pp. 159-168. http://dx.doi.org/10.1007/s10035-010-0222-7

[9.] Weigler F., Scaar H., Mellmann J.: 2012. Investigation of particle and air flows in a mixed flow dryer. Drying Technology 30 (15), pp. 1730-1741.

http://dx.doi.org/10.1080/ 07373937.2012.703742

[10.] Mellmann J., Iroba K. L., Metzger T., Tsotsas E., Mészáros C., Farkas I.: 2011. Moisture Content and Residence
Time Distributions in Mixed- Flow Grain Dryers. Biosystems Engineering 109, pp. 297-307.

http://dx.doi.org/10.1016/j.biosystemseng.2011.04.010

[11.] Cundall P. A. 1971. A computer model for simulating progressive large scale movements in blocky rock systems, Proceedings of the symposium of the international society of rock mechanics (Nancy France), Vol. 1, Paper No. II-8

[12.] Cundall P. A., Strack O. D. L.: 1979. A discrete numerical model for granular assemblies, Geotechnique, 29(1), pp. 47-65. http://dx.doi.org/10.1680/geot.1979.29.1.47

[13.] Mühlbauer W.: 2009. Handbook of Grain Drying; AgriMedia Verlag: Clenze, Germany, 2009.

[14.] Matthies H. J.: 1956. Der Strömungswiderstand beim Belüften landwirtschaftlicher Erntegüter. Aus den Arbeiten des Institutes für Landmaschinen der Technischen Hochschule Braunschweig

[15.] Mellmann J., Weigler F., Scaar H., Teodorov T.: 2011. Dächerschachttrockner zur Trocknung von Schüttgut (Mixedflow dryer for drying of bulk solids). European patent, EP 11180103 